\title{
The long and winding road of non steroidal antinflammatory drugs and paracetamol in cancer pain management: A critical review
}

\author{
Sebastiano Mercadante ${ }^{a, b, *}$, Antonino Giarratano ${ }^{a, b}$ \\ a La Maddalena Cancer Center, Palermo, Italy \\ ${ }^{\mathrm{b}}$ University of Palermo, Italy \\ Accepted 4 January 2013
}

\section{Contents}

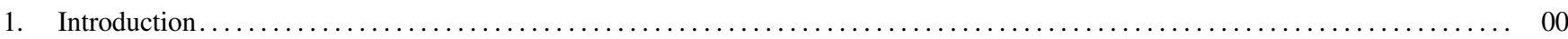

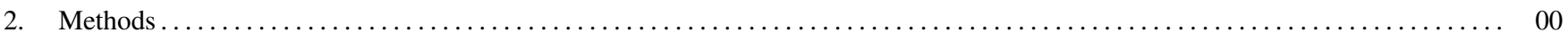

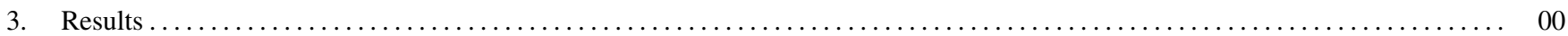

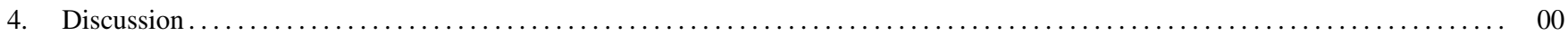

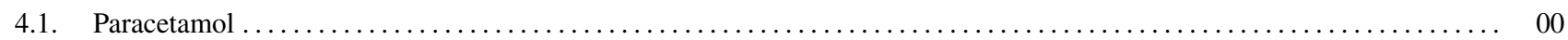

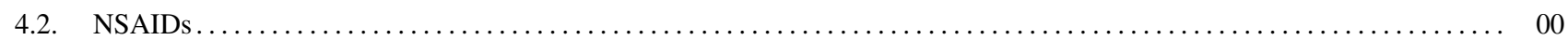

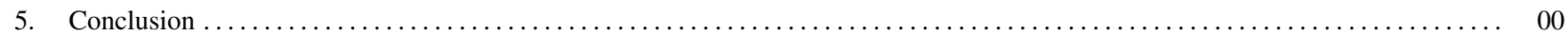

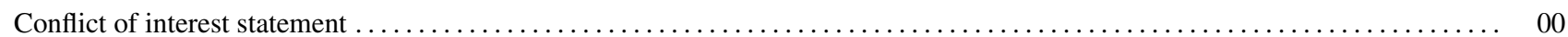

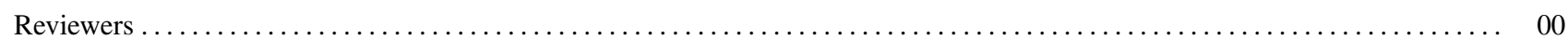

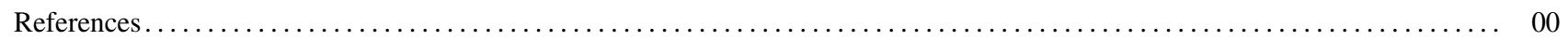

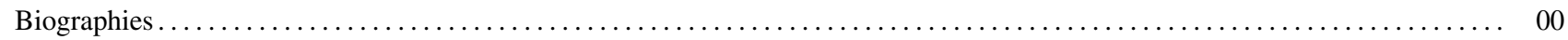

\begin{abstract}
The aim of this review was to assess the value of NSAIDs and paracetamol in patients with cancer pain to update a previous review performed ten years ago on this topic. The approach was analytic and based on clinical considerations, rather than on raw evidence, which often does not provide useful information in clinical practice. Both published reports from an extensive search of electronic data bases were collected from January 2001 to December 2011. A free-text search method was used including the following words and their combination: “Anti-inflammatory drugs OR paracetamol OR acetaminophen” AND/OR “cancer pain”. Any randomized-controlled trial was considered.

Thirteen reports fulfitted inclusion criteria in this systematic review. Randomized trials have been performed by using different modalities of intervention. Single drugs added on opioid therapy or during opioid substitution with opioids as rescue drugs through a patient controlled analgesia, were compared with placebo or between them. Five studies regarded paracetamol. Other four studies assessed the efficacy dipyrone, ketorolac, dexketoprofen, and subcutaneous ketoprofen in cancer pain management, mainly on top of an opioid regimen. The role of paracetamol and NSAIDs in the management of cancer pain still remains controversial. The papers published in this last decade were unable to answer the main questions. There is no proof that they should be used to start the treatment and how long they should be administered when opioid treatment is added on top. While paracetamol seems to be devoid of any benefit, particularly if given at usual clinical doses which should be less than $4 \mathrm{~g}$ /day, ketorolac seems to provide an additive analgesic effect even in patients receiving different doses of opioids. The main indication from the analysis of these data is that NSAIDs could be given in patients receiving opioids, evaluating their benefit and weight on opioid therapy in individual patients who have a favorable response to justify a prolonged use.
\end{abstract}

(C) 2013 Elsevier Ireland Ltd. All rights reserved.

Keywords: Cancer pain; Anti-inflammatory drugs; Paracetamol

\footnotetext{
* Corresponding author at: La Maddalena Cancer Center, Via San Lorenzo 312, 90146 Palermo, Italy. Tel.: +39 0916806521; fax: +39 0916806110. E-mail addresses: terapiadeldolore@lamaddalenanet.it, 03sebelle@gmail.com (S. Mercadante).
} 


\section{Introduction}

According to the World Health Organization (WHO), non steroidal anti-inflammatory drugs (NSAIDs) and paracetamol (PAR) are prescribed alone as first step, or in association to opioids for the subsequent analgesic ladder steps [1]. The rationale for adding this class of drugs to an opioid regimen is to improve the balance between analgesia and adverse effects by either increasing analgesia without adding adverse effects or by maintaining analgesia with less adverse effects, providing an opioid-sparing effect. Concerns about NSAIDs are related to their adverse effects and the use of this class of drugs remains debatable, particularly when they are used first, and then continued with opioids in the other steps in the long-term treatment, when their efficacy cannot be evaluated due to the analgesic covering offered by opioids, or in elderly [2]. Evidence-based reviews often provide raw data which do not seem always applicable in the clinical setting due to the rigid criteria of selection. For example, conclusions suggesting to increase the dose of NSAIDs to a maximum acceptable dose [3] may be not advisable from a clinical point of view. Moreover, these reviews focused on the level of methodology [4], rather than the clinical rationale of the study, which is fundamental for a consequent clinical application in daily practice. Finally, many studies reviewed were really old in terms of methodology, questions posed, and drugs used. The aim of this review was to assess the value of NSAIDs and paracetamol in patients with cancer pain to update a previous review performed ten years ago on this topic [5]. The approach was analytic and based on clinical considerations, rather than on raw evidence, which often does not provide useful information in clinical practice (Tables 1 and 2).

\section{Methods}

Both published reports from an extensive search of electronic data bases, including MEDLINE, PUBMED,
CANCERLIT, and EMBASE were collected from January 2001 to December 2011. A free-text search method was used including the following words and their combination: "Antiinflammatory drugs OR paracetamol OR acetaminophen" AND/OR "cancer pain". Hand searching of relevant journals, and European conference proceedings were also considered. The references of all relevant reports and review articles were searched for additional trials. The inclusion criteria was randomized-controlled trial performed in cancer patients.

\section{Results}

The literature search retrieved 3703 papers. All abstracts were read by the authors and thirteen reports fulfitted inclusion criteria in this systematic review. Four papers were not considered, as paracetamol was used in combination with hydrocodone and compared with tramadol [6], in combination with codeine and compared with hydrocodoneparacetamol [7], and in combination with oxycodone and compared with placebo in patients who were receiving discrete doses of transdermal fentanyl or morphine [8], and in another study ibuprofen was included in a compound containing cobrotoxin and tramadol [9]. Randomized trials have been performed by using different modalities of intervention. Single drugs added on opioid therapy or during opioid substitution with opioids as rescue drugs through a patient controlled analgesia, were compared with placebo or between them. Five studies regarded paracetamol. Other four studies assessed the efficacy dipyrone, ketorolac, dexketoprofen, subcutaneous ketoprofen, in cancer pain management, mainly on top of an opioid regimen.

\section{Discussion}

In a previous review updated to 2001, the evidence from clinical trials available at that time was of limited amount and

Table 1

Studies of paracetamol. R (randomized), DB (double blind), CO (crossover), P (parallel).

\begin{tabular}{llllll}
\hline Authors & No. & Design & Drug - doses & Results & Comments \\
\hline Axelsson (2003) & 30 & $\begin{array}{l}\text { DB CO } \\
7 \text { days }\end{array}$ & Paracetamol 4 g versus Placebo & $\begin{array}{l}\text { No differences in pain } \\
\text { intensity }\end{array}$ & $\begin{array}{l}\text { Pain level too low } \\
\text { High doses of paracetamol }\end{array}$ \\
Stockler (2004) & 30 & $\begin{array}{l}\text { DB CO } \\
2 \text { days }\end{array}$ & Paracetamol $5 \mathrm{~g}$ versus Placebo & $\begin{array}{l}\text { Significant differences in pain } \\
\text { intensity }\end{array}$ & $\begin{array}{l}\text { High doses of paracetamol } \\
\text { Differences clinically not } \\
\text { significant }\end{array}$ \\
Tasmacouglu (2009) & 43 & $\begin{array}{l}\text { DB P } \\
24 \mathrm{~h}\end{array}$ & $\begin{array}{l}\text { Paracetamol } 4 \mathrm{~g} \\
\text { Morphine PCA versus Placebo } \\
\text { Morphine PCA }\end{array}$ & $\begin{array}{l}\text { No differences in opioid } \\
\text { consumption or pain intensity }\end{array}$ & High doses of paracetamol \\
Israel (2010) & 22 & $\begin{array}{l}\text { DB CO } \\
4 \text { days }\end{array}$ & Paracetamol 2g versus Placebo & $\begin{array}{l}\text { No differences in pain } \\
\text { intensity }\end{array}$ & $\begin{array}{l}\text { Pain was already controlled with } \\
\text { mean doses of 255 mg of oral } \\
\text { morphine }\end{array}$ \\
Cubero (2010) & 50 & $\begin{array}{l}\text { DB P } \\
7 \text { days }\end{array}$ & Paracetamol 1.5 g versus Placebo & $\begin{array}{l}\text { No benefit in analgesia or } \\
\text { time to stabilization }\end{array}$ & $\begin{array}{l}\text { Add-on opioid switching to } \\
\text { methadone. No data on final } \\
\text { doses of methadone }\end{array}$ \\
\hline
\end{tabular}


Table 2

Studies of NSAIds. R (randomized), DB (double blind), CO (crossover), P (parallel).

\begin{tabular}{lcllll}
\hline Authors & No. & Design & Drug - doses & Results & Comments \\
\hline Duarte (2007) & 34 & $\begin{array}{l}\text { R DB CO } \\
2 \text { days }\end{array}$ & Dipyrone 2 g versus Placebo & $\begin{array}{l}\text { Better pain control with } \\
\text { dipyrone }\end{array}$ & $\begin{array}{l}\text { Patients receiving } 60 \mathrm{mg} \text { of oral } \\
\text { morphine } \\
\text { Pain remained uncontrolled and } \\
\text { placebo phase after crossing-over } \\
\text { was better }\end{array}$
\end{tabular}

$\begin{array}{lrll}\text { Mercadante (2002) } & 47 & \begin{array}{l}\text { R P } \\ 4 \text { weeks }\end{array} & \begin{array}{l}\text { Ketorolac } 60 \mathrm{mg} \text { versus } \\ \text { Non-ketorolac }\end{array} \\ \text { Rodriguez (2003) } & 115 & \begin{array}{l}\text { R DB P } \\ 7 \text { days }\end{array} & \begin{array}{l}\text { Dexketoprofen } 25 \mathrm{mg} \text { versus } \\ \text { Ketorolac } 40 \mathrm{mg}\end{array} \\ \text { Moselli (2010) } & 172 & \begin{array}{l}\text { Semi C } \\ 4 \text { weeks }\end{array} & \begin{array}{l}\text { Ketoprofen } 700-1400 \mathrm{mg} \text { added } \\ \text { to SC morphine versus SC } \\ \text { morphine only }\end{array}\end{array}$

Better analgesia and opioid-sparing effect

Dexketoprofen at least similar to ketorolac

Better pain control and less opioid consumption
Patients receiving morphine in escalating doses

Pts with bone pain

Unclear opioid consumption (use of an integrated score)

Dose increments proportional to pain intensity. Control group was chosen based on contraindications to NSAIDs. quality. NSAIDs could not be considered analgesics for a specific type or cause of pain, but may provide additive analgesia in patients receiving opioids. The simple finding of an opioid sparing effect may be questioned in cancer pain treatment and should not merely be an indication to add NSAIDs to an opioid regimen, as the same level of analgesia can be achieved increasing opioid dose. It could be questioned whether the addiction of NSAIDs to a therapeutic regime is worth exposing the patients to the side effects of another medication, although the use of NSAIDs may be useful when the increases in opioid dosage determine the occurrence of opioid toxicity in individuals presenting a significant analgesic response [5].

From the analytical revision of the selected papers in the last ten years, many flaws were noticed regarding the methodology and design chosen by authors to demonstrate a construct to transfer in clinical practice. Therefore, limited information was added to literature to provide specific guidelines.

\subsection{Paracetamol}

Paracetamol is considered a safer non opioid analgesic in comparison with NSAIDs, and is considered the first choice in many guidelines for the management of non cancer pain $[10,11]$. However, its efficacy in cancer patients often receiving oioids for their background analgesia should be demonstrated and has been the subject of research in this last decade only in a few studies. A randomized double-blind cross-over placebo-controlled trial was performed to ascertain whether paracetamol has a clinically significant additive analgesic effect to morphine in 30 advanced cancer patients with well-controlled pain [12]. Patients received paracetamol $1000 \mathrm{mg}$ or placebo four times a day for a week. The following week patients crossed over to receive the other treatment. Thirty patients receiving a median dose of oral morphine of $70 \mathrm{mg}$ completed both the study weeks. No differences in pain level between the week with paracetamol and the week with placebo could be detected. However, patients included in the study had a median pain level of $2 / 10$ on a numerical scale of $0-10$. With this level of pain it is quite difficult to observe any differences because of a floor effect. Data remain inconclusive, as the analgesic effect of paracetamol was not explored in patients with pain, because patients already had an optimal pain control, and opioid consumption, for example a reduction in doses, during the study weeks was not reported. Finally paracetamol doses proposed seem to be relatively high, particularly for patients at high risks and this use cannot advised in clinical practice.

In a small double-blind randomized crossover study, paracetamol was administered in doses of $1 \mathrm{~g}$ every $4 \mathrm{~h}$ five times per day ( $5 \mathrm{~g} /$ day), for two days in 30 patients receiving mean doses of oral morphine equivalents of $200 \mathrm{mg} /$ day and having moderate pain $(4 / 10$ on a numerical scale $0-10)$ [13]. While significant, the differences in pain intensity were very low ( 0.4 for the numerical scale $0-10$ ), in patients receiving paracetamol, although authors report that some patients could benefit a lot. No differences in preference, breakthrough doses or adverse effects were reported. The positive interpretation is against clinical observations which have shown that, on average, a reduction of approximately two points or a reduction of approximately $30 \%$ in the pain intensity represent a clinically important difference [14]. Also, the modalities and doses of paracetamol were of concern (every four hours five times per day), the nightly dose being skipped, leaving the patient devoid of the potential analgesic effect of paracetamol for sleeping hours. A two days study is probably insufficient to test an analgesic effect in chronic pain. Finally, paracetamol doses exceeding $4 \mathrm{~g}$ /day are problematic for the risk of hepatic damage in a population at risk such as elderly cancer patients.

For instance, these data were contradicted by other studies. In a pain clinic, 43 patients with non-neuropathic pain who were receiving step 2 treatment and having a pain intensity of $\geq 4 / 10$ were selected for a randomized double-blind controlled study. They received $1 \mathrm{~g}$ of paracetamol intravenously or saline every $6 \mathrm{~h}$. A patient-controlled analgesia with 
intravenous morphine was offered with a bolus dose of $1 \mathrm{mg}$ and a locking time of $5 \mathrm{~min}$ [15]. Pain intensity decreased in both groups, but no significant differences were found between the groups. Similarly, no differences in morphine consumption were observed. It is likely that this use of morphine would have flattened any possible influence of paracetamol. Thus, despite its favorable safety, intravenous administration of paracetamol ( $4 \mathrm{~g} /$ day $)$ did not add any benefit over the control of cancer pain in terms of increate in analgesic efficacy or decrease in morphine consumption.

In a randomized double-blind, placebo-controlled, crossover trial the adjuntive use of paracetamol with strong opioids was assessed. Patients receiving a median dose of $255 \mathrm{mg}$ of oral morphine equivalents, were treated with $500 \mathrm{mg}$ of paracetamol four times daily for five days and five days with placebo in a randomized order. 22 patients concluded the study. No statistically differences in pain intensity (mean difference 0.16 on a numerical scale $0-10$ ) and breakthrough analgesics, as well intensity of adverse effects, were observed [16]. However, patients had a relatively well controlled pain, and a floor effect could have minimized the additive analgesic effect.

Finally, paracetamol was used to assist opioid switching from morphine to methadone in a randomized, doubleblind, placebo-controlled study [17]. Whatever the reason for switching, possibly uncontrolled pain and/or adverse effects, 50 patients having unfavorable balance between pain and adverse effects, did not changed their analgesic regimen for one week. Observing a patient in a critical situation of poor analgesia and adverse effects, without any therapeutic intervention for one week is unrealistic in the real world The addition of paracetamol, $750 \mathrm{mg}$ every $6 \mathrm{~h}$ for a seven days period, did not provide any benefit in pain control or time of stabilization of analgesia once methadone was introduced. It would have been interesting to know the doses of methadone achieved in the two groups at time of stabilization, and how the doses were changed during the study period after starting with an inversely proportional ratios used for switching from morphine to methadone.

\subsection{NSAIDs}

Despite the large availability of this class of drugs in the market, including the new generation of COXIBs, only few studies assessed the efficacy of these drugs in cancer pain. Thirty-four ambulatory patients starting $60 \mathrm{mg} /$ day of oral morphine for cancer pain were randomized to receive in a double-blind, cross-over study design, dipyrone in doses of $500 \mathrm{mg}$ orally every $6 \mathrm{~h}$ or placebo. After two days patients received the alternative treatment, while maintaining the same dose of morphine. Pain was still uncontrolled (7 and 5.5 on a numerical scale, respectively), despite pain control was significantly better with dipyrone [18]. However, after crossing-over patients switched on placebo seemed to have a better pain relief in the subsequent two days. Curiously, authors evaluated as a proof of efficacy that pain improved during the placebo phase, after discontinuation of dipyrone, as it would provide prolonged analgesia. A correct interpretation should be that in the second phase placebo was as least as effective as the active drug.

Ketorolac $60 \mathrm{mg} /$ day was given in addition to patients receiving different doses of morphine in a randomized controlled study. 47 patients were titrated with oral morphine until achieving adequate analgesia. Subsequently, they were randomized to receive ketorolac or not and they could change doses of morphine according to the clinical needs. After a week patients receiving ketorolac showed a better analgesia in comparison with the group of patients receiving oral morphine only. Morphine dose escalation was lower in patients treated with ketorolac and an opioid sparing effect was observed. The use of ketorolac was associated with more gastric discomfort but less constipation and was more convenient in a pharmacologic analysis when added to higher doses of morphine [19]. While this study demonstrated that ketorolac produced a significant analgesic effect independently from the doses of morphine, data on long-term use are lacking.

115 patients with bone cancer pain were randomized for a double-blind evaluation of short-term (7 days) analgesic efficacy of dexketoprofen $25 \mathrm{mg}$ or ketorolac $10 \mathrm{mg}$ every $6 \mathrm{~h}$. The treatments were comparable [20]. A pain rating index of $\geq 10$, calculated from intensity and frequency of pain, analgesic taken, incapacity due to pain, sleep disturbances, and a pain intensity of $\geq 4 / 10$ on a numerical scale 0 to 10 , were used as inclusion criteria, so that it was impossible to know the real opioid consumption.

With regard to the route of administration, when the oral route is impracticable, continuous subcutaneous infusion (CSI) is considered as an effective, simple and cheap alternative. In a prospective observational open-label study, patients with severe pain receiving more than $240 \mathrm{mg}$ of oral morphine equivalents, or patients who failed adequate trials of other strong opioids were treated with a continuous infusion of CSI of ketoprofen added to CSI of morphine [21]. This group of patients was also compared with a concomitant group of patients treated with a CSI of morphine only, because of existing contraindications to NSAIDs. Patients were first converted from oral opioids to CSI of morphine, eventually increasing the dosage by $25-50 \%$ in case of severe pain (7-8/10 and $9-10 / 10$ on a numerical scale, respectively). The dose of ketoprofen was 700 or $1400 \mathrm{mg} /$ day in patients with a pain intensity of $7-8 / 10$ or $9-10 / 10$, respectively and dose of morphine was reduced by $10 \%$ to potentially counterbalance the ketoprofen additive analgesic effect. Thus, authors assumed that doses could be proportional to the high levels of the numerical scale, as it would be a linear relation between an increase in opioid dose and the analgesic effect of the drug. Subsequently the CSI morphine dose were proportionally changed weekly according to the pain severity or the number of boluses of CSI morphine used as breakthrough pain medication. From a large number of patients who underwent CSI, authors analyzed data regarding patients with a follow-up of 
at least one month, 172 receiving morphine ketoprofen CSI and 48 patients receiving morphine CSI only. In the efficacy analysis authors included patients with well controlled pain when they had a pain intensity of $0-2 / 10$. This in contrast with data which indicated a different cut-off to define mild pain, which is acceptable, generally not requiring changes in opioid doses [22]. The opioid consumption seemed to be superior in patients treated without ketoprofen in comparison with patients receiving the CSI with the drug-combination. Only a minority of patients (2.3\%) discontinued ketoprofen due to adverse effects. This was a non randomized controlled study with clear differences of group samples. Data were also difficult to interpret given the rationale of the study protocol which suggested to use increments strictly related to numerical scale numbers. Also, one should argue from the protocol that a level of 6/10 of pain intensity is considered to be a reasonable goal, as dose increments are proposed only when pain intensity get severe $(\geq 7 / 10)$. However pain intensity of $5-6 / 10$ (moderate pain) is estimated to significantly interfere with the quality of patients' life [22], and generally the consequent action is to change the opioid dose.

\section{Conclusion}

The role of paracetamol and NSAIDs in the management of cancer pain still remains controversial. The question on how and when using these drugs has not been resolved. The papers published in this last decade were unable to answer the main questions. There is no proof that they should be used to start the treatment and how long they should be administered when opioid treatment is added on top. Paracetamol seems to be devoid of any benefit, particularly if given at usual clinical doses of less than $4 \mathrm{~g} /$ day. Indeed, ketorolac seems to provide an additive analgesic effect even in patients receiving different doses of opioids. The main suggestion from the analysis of these data is that NSAIDs could be given in patients receiving opioids and evaluating their benefit and weight on opioid therapy in individual patients who have a favorable response to justify a prolonged use. No proof has been provided about the use of this class of drugs as first step of the analgesic ladder.

\section{Conflict of interest statement}

No financial and personal relationships with other people or organizations that could inappropriately influence (bias) their work, including employment, consultancies, stock ownership, honoraria, paid expert testimony, patent applications/registrations, and grants or other funding.

\section{Reviewers}

Giampiero Porzio, M.D., Hospital San Salvatore, Medical Oncology Department, IT-67100, L'Aquila, Italy.
Alonso-Babarro, Ph.D., M.D., Hospital Universitario La Paz, Palliative Care, Paseo Castellana 261, ES-28046 Madrid, Spain.

\section{References}

[1] Ripamonti C, Bandieri E. Pain therapy. Critical Reviews in Oncology/Hematology 2009;70:145-59.

[2] Urban D, Cherny N, Catane R. The management of cancer pain in the elderly. Critical Reviews in Oncology/Hematology 2010;73:176-83.

[3] McNicol E, Strassels SA, Goudas L, et al. NSAIDs or paracetamol, alone or combined with opioids for cancer pain. Cochrane Database of Systematic Reviews 2005:CD005180.

[4] Nabal M, Librada S, Redondo MJ, Pigni A, Brunelli C, Caraceni A. The role of paracetamol and nonsteroidal anti-inflammatory drugs in addition to WHO step III opioids in the control of pain in advanced cancer. mA systematic review of the literature. Palliative Medicine 2012;26:305-12.

[5] Mercadante S. The use of anti-inflammatory drugs in cancer pain. Cancer Treatment Reviews 2001;27:51-61.

[6] Rodriguez RF, Castillo J, Castillo MP, et al. Hydrocodone/ acetaminophen and tramadol chlorhydrate combination tablets for the management of chronic cancer pain: a double-blind comparative trial. Clinical Journal of Pain 2008;24:1-4.

[7] Rodriguez RF, Castillo J, Castillo MP, et al. Codeine/acetaminophen and hydrocodone/acetaminophen combination tablets for the management of chronic cancer pain in adults: a 23 days, prospective, double-blind, randomized, parallel-group study. Clinical Therapeutics 2007;29:581-7.

[8] Sima L, Fang WX, Wu XM, Li F. Efficacy of oxycodone/paracetamol for patients with bone cancer pain: a multicenter, randomized, doubleblind, placebo-controlled trial. Journal of Clinical Pharmacy and Therapeutics 2011;37:27-31.

[9] Xu JM, Song ST, Feng FY, et al. Cobrotoxin-containing analgesic compound to treat chronic moderate to severe cancer pain: results from a randomized, double-blind, cross-over study and from an open-label study. Oncology Reports 2006;16:1077-84.

[10] Chou R, Qaseem A, Snow V, et al. Clinical efficacy assessment subcommittee of the American college of physicians; American College of Physicians; American Pain Society Low Back Pain Guidelines Panel. Diagnosis and treatment of low back pain: a joint clinical practice guideline from the American College of Physicians and the American Pain Society. Annals of Internal Medicine 2007;147:478-91.

[11] Dagenais S, Tricco AC, Haldeman S. Synthesis of recommendations for the assessment and management of low back pain from recent clinical practice guidelines. Spine Journal 2010;10:514-29.

[12] Axelsson B, Borup S. Is there an additive analgesic effect of paracetamol at step 3? A double-blind randomized controlled study. Palliative Medicine 2003;17:724-5.

[13] Stockler M, Vardy J, Pillai A, Warr D. Acetaminophen (paracetamol) improves pain and well-being in people with advanced cancer already receiving a strong opioid regimen: a randomized, doubleblind, placebo-controlled cross-over trail. Journal of Clinical Oncology 2004;22:3389-94.

[14] Farrar JT, Young Jr JP, LaMoreaux L, Werth JL, Poole RM. Clinical importance of changes in chronic pain intensity measured on an 11point numerical pain rating scale. Pain 2001;94:149-58.

[15] Tasmacouglu B, Aydinli I, Keskinbora K, Pekel A, Salihoglu T, Sonsuz A. Effect of intravenous administration of paracetamol on morphine consumption in cancer pain control. Supportive Care in Cancer 2009;17:1475-81.

[16] Israel F, Couns M, Parker G, et al. Lack of benefit from paracetamol (acetaminophen) for palliative cancer patients requiring high-dose strong opioids: a randomized, double-blind, placebo-controlled, 
crossover trial. Journal of Pain and Symptom Management 2010;39: 548-54.

[17] Cubero D, del Giglio A. Early switching from morphine to methadone is not improved by acetaminophen in the analgesia of oncologic patients: a prospective, randomized, double-blind, placebo-controlled study. Supportive Care in Cancer 2010;18:235-42.

[18] Duarte-Souza J, Lajolo P, Pinczowski H, del Giglio A. Adjunct dipyrone in association with oral morphine for cancer-related pain: the sooner the better. Supportive Care in Cancer 2007;15:1319-23.

[19] Mercadante S, Fulfaro F, Casuccio A. A randomized controlled study on the use of anti-inflammatory drugs in patients with cancer pain on morphine therapy: effects on dose-escalation and a pharmacoeconomic analysis. European Journal of Cancer 2002;38:1358-63.

[20] Rodriguez M, Contreras D, Galvez R, et al. Double-blind evaluation of short term analgesic efficacy of orally administered dexketoprofen trometamol and ketorolac in bone cancer pain. Pain 2003;104: $103-10$.

[21] Moselli NM, Cruto M, Nassucco P, Savojardo, Debernardi F. Longterm continuous subcutaneous infusion of ketoprofen combined with morphine: a safe and effective approach to cancer pain. Clinical Journal of Pain 2010;26:267-74.

[22] Serlin RC, Mendoza TR, Nakamura Y, Edwards KR, Cleeland CS. When is cancer pain mild, moderate or severe? Grading pain severity by its interference with function. Pain 1995;61:277-84.

\section{Biographies}

Sebastiano Mercadante was born on 3rd December 1955. He achieved his Doctor's degree with full marks in 1979. He specialized in anesthesiology (1980-1983), University of Palermo; and in science of nutrition (1984-1987), University of Palermo. He is Professor of Palliative Medicine, Postgraduate Master, University of Palermo, and Director of the Anesthesia and Intensive Care Unit, Pain Relief and Palliative Care Unit, La Maddalena Clinic for Cancer, Palermo, Italy. He has given more than 400 hundred lectures at national and international congresses, and is Associated Editor, on the editorial Board and/or referee of more than 30 international peer-reviewed journals in the field of pain and symptom management and anaesthesiology. He has published more than 350 papers in peer-reviewed international journals and is author of more than 40 chapters and books.

He won the Umberto Veronesi award in 2003, the award of excellence in scientific research, American Academy of Hospice and palliative medicine, Boston 2010, the award of the ESMO designed center of integrated oncology and palliative care, Stockolm 2011, John Mendelsohn award, Houston 2013.

Antonino Giarratano, was born in 1961. He achieved his Doctor's degree in 1986 and specialized in Anesthesiology in 1989 at University of Palermo. He was Assistant Professor of Anesthesiolgy and Intensive care (2000-2005). Since 2005 Associate Professor of Anesthesiology and chief of Intensive care at universitary hospital of Palermo. He is Chairman of Regional chapter of national society of Anesthesiologists since 2003, and since 2005 Member of the Italian Society of Anesthesiology and Critical Care Medicine and European Society (ESICM). Since 2004 he is Delegate Chief from Policlinico Health Management for "The Quality" of the Department of Anesthesiology - University of Palermo and Associate Researcher at the Biological and Molecular Department of National Council Research in Palermo. He has been the regional delegate for The Italian Society of Anesthesia and Intensive Care Medicine (2006-2009). Since 2011 is the Director of School of anesthesiology and intensive care medicine of University of Palermo. He published dozen of papers in the filed of intensive care, immunology, and coagularive disordres. 